\title{
Effects of antioxidant enzyme polymorphisms on ozone-induced lung function changes
}

\author{
C. Chen*, ${ }^{*}$, M. Arjomandi, , I.B. Tager*, N. Holland* and J.R. Balmes*,\#
}

ABSTRACT: Chronic exposure to ozone $\left(\mathrm{O}_{3}\right)$ can cause changes in lung function that may reflect remodelling of small airways. It is likely that antioxidant enzyme function affects susceptibility to $\mathrm{O}_{3}$. The aim of the present study was to determine whether polymorphisms in antioxidant enzyme (GSTM1, GSTP1 and NQO1) genes affect the risk of lung function changes related to chronic exposure to $\mathrm{O}_{3}$.

In total, 210 young adults who participated in a previous study, which showed a relationship between lifetime exposure to $\mathrm{O}_{3}$ and decreased lung function, were genotyped. Multivariable linear regression was used to model sex-specific associations between genotypes and $\mathrm{O}_{3}$-related lung function changes, adjusting for height, weight, lifetime exposure to nitrogen dioxide and particles with a $50 \%$ cut-off aerodynamic diameter of $10 \mu \mathrm{m}$, and self-identified race/ethnicity.

The GSTM1-null/NQ01 Pro187Pro-combination genotype was significantly associated with increased risk of an $\mathrm{O}_{3}$-related decrease in mean forced expiratory flow between $25-75 \%$ of forced vital capacity in females (parameter estimate \pm SE $-75 \pm 35 \mathrm{~mL} \cdot \mathrm{s}^{-1}$ ), while the GSTP1 Val105 variant genotypes were significantly associated with greater risk of an $\mathrm{O}_{3}$-related decrease in mean forced expiratory flow at $75 \%$ of forced vital capacity in males $\left(-81 \pm 31 \mathrm{~mL} \cdot \mathrm{s}^{-1}\right)$. GSTM1-null status was not significantly associated with any $\mathrm{O}_{3}$-related changes in lung function in either sex.

The current authors conclude that the effects of antioxidant enzyme gene polymorphisms on the risk of decreased lung function related to chronic exposure to ozone may be modified by sexspecific factors.

\section{KEYWORDS: Antioxidant enzymes, lung function, oxidative injury, ozone}

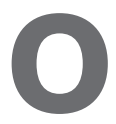
zone $\left(\mathrm{O}_{3}\right)$, a major component of air pollution, is a potent oxidant gas that causes airway injury in human lungs [1]. A large proportion of inhaled $\mathrm{O}_{3}$ (up to $90 \%$ ) is absorbed in the respiratory tract along the entire tracheobronchial tree [2], with the greatest dose being delivered to the peripheral airways at the junction between the conducting and respiratory airways [3]. $\mathrm{O}_{3}$ reacts with respiratory tract lining fluid constituents and cellular membrane components to generate lipid ozonation products (LOP) and reactive oxygen species (ROS), which in turn can cause oxidative damage to other biological molecules [4-6]. Acute exposure to ambient levels of $\mathrm{O}_{3}$ can induce short-term lung function abnormalities and airway inflammation, while chronic exposure may lead to remodelling of the small airways, where deposition is the greatest [7-12].
To minimise the potential for oxidative injury, the human lung has an integrated system of antioxidant enzymes and expendable soluble molecules. This system includes several mechanisms by which ROS are converted to products that are further detoxified by other enzymes. If the oxidant burden is sufficiently great, ROS may overwhelm the antioxidant system leading to a state of "oxidative stress", which is thought to contribute to the pathogenesis of a number of respiratory diseases [13-15]. Although antioxidant defences are available to decrease oxidative stress in the airways, individuals differ in their ability to deal with an oxidant burden; such differences are, in part, determined genetically [16]. This genetic variability may account for the considerable between-subject variability seen in both the lung function and airway inflammatory responses to $\mathrm{O}_{3}[17,18]$.

\section{AFFILIATIONS}

*School of Public Health, University of California, Berkeley, and

\#Lung Biology Center, Dept of Medicine, University of California, San Francisco, CA, USA.

"These authors contributed equally to the present study.

CORRESPONDENCE

J.R. Balmes

University of California

Box 0843

San Francisco

CA 94143-0843

USA

Fax: 14152068949

E-mail: john.balmes@ucsf.edu

Received:

December 082006

Accepted after revision:

June 292007

\section{SUPPORT STATEMENT}

The study was supported by the National Institutes of Health (Bethesda, MD, USA; R01 HL60689 K23 HL83099) and the American Lung Association (New York, NY, USA; Research Training Fellowship).

STATEMENT OF INTEREST

None declared. 
Glutathione S-transferase (GST) enzymes, a superfamily of dimeric phase-II metabolic enzymes, play an important role in the antioxidant defence system. GST enzymes catalyse the conjugation of toxic electrophilic molecules with glutathione and thereby protect cellular macromolecules from damage due to LOP and ROS. The specific GST enzymes that have been proposed as important in antioxidant defence are those of the mu (GSTM), theta (GSTT) and pi (GSTP) classes, each with functional polymorphisms that affect protein expression or function [19].

A common polymorphism in the GSTM1 gene locus, which exists in $30-50 \%$ of the general population $[19,20]$, involves a null allele and results in a complete lack of GSTM enzymatic function. Therefore, the GSTM1 null genotype would be expected to affect the individual's response to $\mathrm{O}_{3}$ exposure, possibly causing increased susceptibility to oxidative injury. Since 2001, the results of several field studies showed that the GSTM1 null genotype is associated with greater acute lung function response and/or respiratory symptom response to $\mathrm{O}_{3}$-induced oxidative stress [21-23]. Other studies have suggested that the GSTM1 null genotype may play a significant role in the development of asthma in response to oxidative stress [24, 25]. In two of the aforementioned studies, a polymorphism (Ser187) of a second antioxidant enzyme, NQO1 (reduced nicotinamide adenine dinucleotide (phosphate): quinone oxidoreductase 1), provided a protective effect among GSTM1 null subjects [21, 25].

Another gene of interest with regard to responses to oxidant pollutants is GSTP1, which is the most abundant GST in lung tissue and has a common A105G polymorphism that results in an Ile105Val amino acid substitution. In the Children's Health Study (CHS), children who were homozygotes for GSTP1 Val105 variant allele had a lower rate of respiratory infections than those with the GSTP1 Ile/Ile105 wild type but, somewhat surprisingly, they also had a slower rate of lung function growth [26, 27]. A recent study showed that the GSTP1 Val/ Val105 genotype was associated with increased $\mathrm{O}_{3}$-related respiratory symptoms [23]. In contrast, in a small $(n=19)$ controlled exposure study of sensitised allergic rhinitic adults, in which nasal instillation of diesel exhaust particles (known to cause oxidative stress) enhanced specific allergic responses to ragweed, GILLILAND et al. [28] showed that the GSTM1 null genotype increased susceptibility and the GSTP1 Val105 variant had a protective effect.

Considered together, these human studies provide suggestive evidence that polymorphisms of phase-II enzymes contribute to susceptibility to inhaled oxidant-induced toxicity. In a recent epidemiological study [11], the current authors' group demonstrated an association between lifetime exposure to ambient $\mathrm{O}_{3}$ and decreased lung function parameters consistent with small airway remodelling. To determine whether the GSTM1 null, GSTM1 null/NQO1 homozygous Pro187 combination or GSTP1 Val105 variant genotypes had an effect on the observed relationship between lifetime exposure to $\mathrm{O}_{3}$ and decreased lung function, the subjects who participated in the previous study [11] were genotyped, and it was assessed whether these genotypes affected the risk of $\mathrm{O}_{3}$-induced lung function changes. The current authors selected these three genotypes for study on the basis of the previous literature reviewed above.

\section{METHODS}

The protocol for the study was approved by the Committee for the Protection of Human Subjects, University of California, Berkeley (UCB; CA, USA), and the Committee on Human Research, University of California, San Francisco, CA, USA. Written informed consent was obtained from all study participants once eligibility was established.

\section{Study design}

The overall design of the study has been previously presented in detail [11]. Briefly, a convenience sample of 255 freshman undergraduates at UCB was recruited in three waves that began on April 10, 2000, February 12, 2001 and February 6, 2002. All waves ended in the first week of June. Subjects were studied between February-May when students from Los Angeles (LA; CA, USA) would not have been exposed to high summertime $\mathrm{O}_{3}$ concentrations.

Students were eligible based on the following criteria: 1) lifelong resident of the greater LA or San Francisco Bay (SF) area prior to enrolment at UCB; 2) lifetime never-smoker, 3) no history of chronic respiratory disease (history of asthma before age 12 yrs was permitted, provided that student had no symptoms and had not taken any medication at any time after age 12 yrs $(n=6))$; and 4) no physical impairment that would hinder performance of spirometry. Location of all residences within the geographical boundaries for the study was confirmed by study personnel.

\section{Ozone exposure assessment}

A detailed description of the creation of lifetime cumulative $\mathrm{O}_{3}$ exposure for each subject has been previously reported [10]. Briefly, lifetime residential history was reconstructed with a standardised questionnaire and air pollutant $\left(\mathrm{O}_{3}, \mathrm{NO}_{2}\right.$ and particles with a $50 \%$ cut-off aerodynamic diameter of $10 \mu \mathrm{m}$ (PM10)) concentrations were assigned for each month of life to each residential location. Air quality data were acquired from the California Air Resources Board (ARB; CD No. PTSD-02017-CD), the Aerometric Information Retrieval System and by special requests to the ARB. Monthly mean measures of $\mathrm{O}_{3}$ were interpolated spatially from air quality monitoring stations to the residence locations with inverse distance weighting and a maximum of three monitoring stations for each interpolation (maximum interpolation radius of $50 \mathrm{~km}$ ). The details and reliability of the exposure assignment method have been previously published [10, 29, 30]. Briefly, two basic models are fitted in order to estimate lifetime pollutant $\left(\mathrm{O}_{3}\right.$, $\mathrm{NO}_{2}$ and $\mathrm{PM} 10$ ) exposure. There was no significant difference in the association between lifetime $\mathrm{O}_{3}$ exposure and lung function between the two models. In the present study, the socalled "ecological" model was used, which omitted estimates of time spent outdoors and used only the residence-specific monthly average interpolated pollutant concentrations.

\section{Subject characteristics}

Of the 255 enrolled subjects, 226 had sufficient DNA available for genotyping. The 29 subjects who were not genotyped were mostly female. In total, 16 subjects did not self-identify with one of three main racial/ethnic groups (Asians/Pacific 
Islanders, Caucasians and Hispanics) and were excluded from further analysis. Thus, 210 subjects were used in the final analysis (table 1 ). Of these, $\sim 43 \%$ were male and $60 \%$ were lifelong residents of the LA area. Most of the participants were Asians (54\% of males and $60 \%$ of females) or Caucasians $(39 \%$ of males and $28 \%$ of females). There were no significant sex differences in lifetime exposure estimates of pollutants $\left(\mathrm{O}_{3}\right.$, PM10 and $\mathrm{NO}_{2}$ ). Although subjects who grew up in LA had higher median estimated lifetime exposures than those from the SF area, distributions between the two regions overlapped and represented a continuum of individual exposure.

\section{Antioxidant enzyme genotyping}

DNA was isolated from clot with a Qiamp Blood DNA Maxi kit (Qiagen Inc., Santa Clarita, CA, USA) in accordance with the manufacturer's instructions and stored at $-80^{\circ} \mathrm{C}$ until use. Genotyping for the GSTM1 polymorphism was carried out following a previously reported protocol [31]. The TaqMan real time PCR method was used to detect polymorphisms of GSTP1 (A105G) and NQO1 (C187T). Primers and probes for the single-nucleotide polymorphisms were custom-designed by Applied Biosystems Inc. (Foster City, CA, USA; see online data supplement for primer sequences). The reaction was carried out in TaqMan Universal Master Mix with a 7900 Real-Time PCR machine (Applied Biosystems). Quality assurance procedures included: assessment of randomly distributed blank samples; duplicates of randomly selected samples; manual

\begin{tabular}{|c|c|c|}
\hline & Males & Females \\
\hline Subjects $n$ & 90 & 120 \\
\hline \multicolumn{3}{|l|}{ Age yrs } \\
\hline$<18$ & 46 & 57 \\
\hline 19 & 49 & 41 \\
\hline$\geqslant 20$ & 5 & 2 \\
\hline \multicolumn{3}{|l|}{ Ethnicity $\#$} \\
\hline Asian/Pacific Islander & 54 & 60 \\
\hline Caucasian & 39 & 28 \\
\hline Hispanic & 7 & 12 \\
\hline \multicolumn{3}{|l|}{ Residence } \\
\hline San Francisco Bay Area $^{+}$ & 41 & 47 \\
\hline Los Angeles ${ }^{\S}$ & 56 & 48 \\
\hline Both $f$ & 3 & 5 \\
\hline \multicolumn{3}{|l|}{ Estimated lifetime exposure } \\
\hline $\mathrm{O}_{3}{ }^{\# \#} \mathrm{ppb}$ & 37 (14-59; 28-46) & $33(26-42 ; 9-57)$ \\
\hline \multicolumn{3}{|l|}{$\mathrm{PM} 10^{\pi} \mathrm{mcg} \cdot \mathrm{m}^{-3}$} \\
\hline Prior to 1987 & $73(33-115 ; 53-94)$ & 69 (23-91; 52-92) \\
\hline 1987 and later & $36(11-61 ; 26-44)$ & $29(9-50 ; 26-43)$ \\
\hline $\mathrm{NO}_{2}^{++} \mathrm{ppb}$ & $29(9-48 ; 22-41)$ & $26(5-47 ; 21-40)$ \\
\hline
\end{tabular}

Data are presented as \% or median (range; interquartile range), unless otherwise stated. PM10: particles with 50\% cut-off aerodynamic diameter of $10 \mu \mathrm{m} .{ }^{*}$ : self-reported; ": lifetime residence before enrolment at the University of California, Berkeley, CA, USA; ${ }^{+}$: latitude $37-38.5^{\circ}$ and longitude $121.67-$ $123^{\circ}$; ' : latitude $32-35^{\circ}$ and longitude $115.5-120.75^{\circ} ;$ : spent equal time in both Los Angeles and San Francisco [11]; \#\#: monthly 8-h average; " average; ${ }^{++}$: average calls assisting automated calling for Taqman analysis; and repeated additional analysis from independently isolated DNA samples from the same subjects. Assays were repeated for all low-confidence samples until a reliable call was obtained. The genotype frequencies for GSTM1, GSTP1, and GSTM1 null/ NQO1 did not deviate from Hardy-Weinberg equilibrium.

\section{Spirometry}

Forced expiratory volumes were obtained in the sitting position with nose clip with a Collins Survey rolling seal spirometer (Warren E. Collins Co., Braintree, MA, USA) with two modifications to the standard criteria of the American Thoracic Society [32], details of which have been previously reported [33]. Forced vital capacity (FVC), forced expiratory volume in one second (FEV1), mean forced expiratory flow between $25-75 \%$ of FVC (FEF25-75\%) and mean forced expiratory flow at $75 \%$ of FVC (FEF75\%) were recorded. The FEF25-75\%/FVC ratio, an estimate of the reciprocal of the time constant of the lung [34] and a reflection of intrinsic airway size [33], was also calculated. This measure was used, in part, to control for racial/ethnic differences in airway size [11]. Sexspecific models for each measure of lung function were fit based on height, weight and age as described previously [11, 31]. There was no association between any measure of lung function and history of asthma before age $12(n=6)$ or history of second-hand tobacco smoke exposure $(n=34)$ [11].

\section{Statistical analysis}

Genotypes for antioxidant enzyme polymorphisms were coded as follows: GSTM1 wild type (positive) $=0$ or null $=1$ and GSTP1 Ile105 wild type (homozygous AA) $=0$ or Val105 variant (heterozygous AG or homozygous GG)=1. The GSTM1/NQO1 combination genotype included only GSTM1 null subjects and used the following coding: NQO1 wild type Pro187 (homozygous CC) $=0$ or Ser187 variant (heterozygous CT or homozygous TT) $=1$. Because it is well established that lung function differs between males and females [35], sex-specific multivariable linear regression was used to model lung function variables. Except for FEV1, natural logarithmic transformations of lung function variables were used. The initial model for each lung function variable included the subject's height, weight and race/ ethnicity, and each genotype and was based on the optimal model among several tested, as previously described [11, 31]. Final models included height, weight, race/ethnicity, genotype and lifetime exposures to $\mathrm{O}_{3}, \mathrm{PM} 10$ and $\mathrm{NO}_{2}$, as previously described $[11,31]$. The combined genotype, GSTM1·NQO1, was treated as single term, based on reported interactions between the null allele of GSTM1 and the serine polymorphism for NQO1. The FEF25-75\%/FVC ratio was treated as an interaction term for reasons previously discussed [11]. Finally, measurement error correction procedures were not used for the $\mathrm{O}_{3}$ effects, since the current authors have shown previously [11] that the coefficients for $\mathrm{O}_{3}$ and the $\mathrm{O}_{3}-(\mathrm{FEF} 25-75 \% / \mathrm{FVC})$ interaction were not affected by such corrections.

\section{RESULTS}

Allele and genotype frequencies differed significantly among ethnicities (table 2). For GSTM1, frequency of GSTM1 null status was significantly different for both Hispanics (60\%) and Caucasians (57\%) compared with Asians (44\%). For NQO1, the NQO1 T allele (Ser187) was significantly lower in Caucasians 
(18\%) than Asians (40\%) and Hispanics (35\%). For GSTP1, the $\mathrm{G}$ allele (Val105) was significantly more common in Hispanics (48\%) than Caucasians (20\%) and Asians (29\%).

\section{Effect of genotype on lung function}

The effects of the three polymorphisms on lung function can be seen in table 3 (see online data supplement for complete model parameter estimates). In males, GSTM1 null homozygosity was associated significantly with decreased FEF25-75\% $\left(-98 \mathrm{~mL} \cdot \mathrm{s}^{-1}\right.$; $95 \%$ confidence interval (CI): $\left.-15--181 \mathrm{~mL} \cdot \mathrm{s}^{-1}\right)$. However, when the GSTM1 null genotype occurred in combination with NQO1 wild type (homozygous Pro187), this association was no longer significant. Similarly, GSTM1 null was associated significantly with decreased FEF75\% $\left(-133 \mathrm{~mL} \cdot \mathrm{s}^{-1} ; 95 \% \mathrm{CI}\right.$ : -27- -240 $\mathrm{mL} \cdot \mathrm{s}^{-1}$ ) while GSTM1 null/NQO1 wild-type combination genotype was not. For FEV1, no association between either the GSTM1 null or GSTM1 null/NQO1 wild-type combination genotype was found in males (data not shown).

In contrast to males, there were no significant changes in FEF25-75\% and FEF75\% for the GSTM1 null variant alone in females. However, a decrease in FEF25-75\% $\left(-136 \mathrm{~mL} \cdot \mathrm{s}^{-1} ; 95 \%\right.$ CI: $\left.-29--243 \mathrm{~mL} \cdot \mathrm{s}^{-1}\right)$ and FEF75\% $\left(-125 \mathrm{~mL} \cdot \mathrm{s}^{-1} ; 95 \% \mathrm{CI}:-2-\right.$ $-253 \mathrm{~mL} \cdot \mathrm{s}^{-1}$ ) was associated significantly with the GSTM1 null/NQO1 wild-type combination genotype. For FEV1, there was no association with either GSTM1 null or GSTM1 null/ NQO1 wild type-combination genotype in females (data not shown).

\begin{tabular}{|c|c|c|c|c|}
\hline \multirow[t]{2}{*}{ TABLE 2} & \multicolumn{4}{|c|}{$\begin{array}{l}\text { Genotype and allele frequencies by race/ } \\
\text { ethnicity }\end{array}$} \\
\hline & $\begin{array}{c}\text { Asian/Pacific } \\
\text { Islander }\end{array}$ & Caucasian & Hispanic & Total \\
\hline \multicolumn{5}{|l|}{ GSTM1 } \\
\hline Null & $56(65)$ & $43(30)$ & $40(8)$ & $50(103)$ \\
\hline Present ${ }^{\#}$ & $44(52)$ & $57(39)^{*}$ & $60(12)^{*}$ & $50(103)$ \\
\hline \multicolumn{5}{|l|}{ NQ01 } \\
\hline $\mathrm{CC}$ & $40(47)$ & $66(45)$ & $50(10)$ & $50(102)$ \\
\hline $\mathrm{CT}$ & $40(47)$ & $31(21)$ & $30(6)$ & $36(74)$ \\
\hline$\pi T$ & $20(24)$ & $3(2)$ & $20(4)$ & $15(30)$ \\
\hline \multicolumn{5}{|l|}{ Alleles } \\
\hline C & 60 & 82 & 65 & 67 \\
\hline$T$ & 40 & $18^{*}$ & 35 & 33 \\
\hline \multicolumn{5}{|l|}{ GSTP1 } \\
\hline AA & $63(74)$ & $51(35)$ & $30(6)$ & $56(115)$ \\
\hline$A G$ & $34(40)$ & $41(28)$ & $45(9)$ & $37(77)$ \\
\hline$G G$ & $3(4)$ & $9(6)$ & $25(5)$ & $7(15)$ \\
\hline \multicolumn{5}{|l|}{ Alleles } \\
\hline A & 80 & 71 & 53 & 74 \\
\hline $\mathrm{G}$ & 20 & 29 & $48^{*}$ & 26 \\
\hline \multicolumn{5}{|c|}{ GSTM1 null/NQO1 } \\
\hline CT or TT & $64(41)$ & $41(12)$ & $63(5)$ & $59(58)$ \\
\hline $\mathrm{CC}$ & $36(23)$ & $59(17)$ & $38(3)$ & $41(43)$ \\
\hline
\end{tabular}

Data are presented as \% or \% (n). ${ }^{*}$ : homozygous (2 alleles) or heterozygous (1 allele). ${ }^{*} p<0.05$ by logistic regression, with Asian/Pacific Islander as referent group.
Finally, effects of GSTP1 Val105 in male and females subjects also differed. The variant allele was marginally associated with changes in both FEF25-75\% and FEF75\% in both sexes. However, for males the variant allele was nonsignificantly associated with decreases in these flow measures, while for females the trend is for an increase. No associations were found between GSTP1 val105 and FEV1 in either males or females (data not shown).

\section{Effect of genotype and lifetime $\mathrm{O}_{3}$ exposure on lung function}

To explore the effect of genotype on risk of lung function changes due to chronic exposure to $\mathrm{O}_{3}$, the final models of the present study included lifetime exposure to $\mathrm{O}_{3}, \mathrm{PM} 10$ and $\mathrm{NO}_{2}$, and an interaction term for $\mathrm{O}_{3} \cdot(\mathrm{FEF} 25-75 \% / \mathrm{FVC})$, in addition to the variables included in the initial genotype-only models. When this approach was used in sex-specific models for GSTM1 null and GSTM1 null/NQO1 wild-type combination genotypes, the only significant association with risk of $\mathrm{O}_{3}$ related decreased lung function was observed in females for the combination genotype and FEF25-75\% (table 4).

The GSTP1 variant allele, however, was associated with greater risk of $\mathrm{O}_{3}$-related decreases in FEF25-75\% $(\mathrm{p}<0.11)$ and $\mathrm{FEF} 75 \%$ in males $(\mathrm{p}<0.04$; table 4$)$ after adjustment for lifetime $\mathrm{O}_{3}$ exposure and its interaction with airway size. The magnitude of the effect can be estimated from the final model based on the male-specific 25th percentile $\mathrm{FEF} 25-75 \%$ / FVC ratio and mean lifetime $\mathrm{O}_{3}$ exposure difference between subjects from LA and SF (17 ppb). For males who are homozygous GSTP1 Iso105 (wild type), the $17 \mathrm{ppb}$ lifetime $\mathrm{O}_{3}$ exposure difference results in a $20 \mathrm{~mL} \cdot \mathrm{s}^{-1}\left(95 \% \mathrm{CI}:-18--22 \mathrm{~mL} \cdot \mathrm{s}^{-1}\right)$ decrease in FEF75\%. For males carrying the Val105 variant GSTP1 allele, the $17 \mathrm{ppb}$ lifetime $\mathrm{O}_{3}$ exposure difference results in a $28 \mathrm{~mL} \cdot \mathrm{s}^{-1}(95 \% \mathrm{CI}$ $\left.-26--30 \mathrm{~mL} \cdot \mathrm{s}^{-1}\right)$ decrease in FEF75\%. The magnitude of the combined effect of the GSTP1 variant allele and lifetime $\mathrm{O}_{3}$ exposure is almost $50 \%$ less for males with the median FEF25$75 \% / \mathrm{FVC}$ ratio (i.e. larger airway size).

For females, the GSTP1 Val105 variant allele did not have a statistically significant effect on lifetime $\mathrm{O}_{3}$-related decreases in lung function.

\section{DISCUSSION}

In a previous study, the current authors showed that estimated lifetime exposure to ambient $\mathrm{O}_{3}$ in a cohort of adolescents was associated with reduced levels of lung function measures that reflect the function of small airways [11]. It was found that, without consideration of the effect of $\mathrm{O}_{3}$, the male subjects of the cohort with the GSTM1 null genotype had lower lung function measures that reflect small airways function, compared with those without this genotype. The current authors did not find this same gene effect for female subjects of the cohort. However, when lifetime exposure to $\mathrm{O}_{3}$ was included in the models, no deleterious role for GSTM1 null was found on lung function in either sex, although the GSTM1 null/ NQO1 wild-type combination genotype was associated with increased risk of $\mathrm{O}_{3}$-related decreases in $\mathrm{FEF} 25-75 \%$ in females.

A novel finding of the present study is that the GSTP1 Val105 variant genotype was a risk factor for decreased lung function in association with lifetime exposure to $\mathrm{O}_{3}$ in males. 
TABLE 3 Genotype-only model of lung function

\begin{tabular}{|c|c|c|c|c|c|c|}
\hline & \multicolumn{6}{|c|}{ Parameter estimates } \\
\hline & \multicolumn{3}{|c|}{ Males } & \multicolumn{3}{|c|}{ Females } \\
\hline \multicolumn{7}{|l|}{ FEF $25-75 \%$} \\
\hline \multicolumn{7}{|l|}{ FEF75\% } \\
\hline Genotype & $-0.058 \pm 0.054$ & $-0.133 \pm 0.055^{\star}$ & $-0.049 \pm 0.064$ & $0.034 \pm 0.052$ & $-0.01 \pm 0.051$ & $-0.125 \pm 0.065^{\star}$ \\
\hline Adjusted $\mathrm{R}^{2}$ & 0.17 & 0.21 & 0.36 & 0.10 & 0.09 & 0.17 \\
\hline $\begin{array}{l}\text { Data are prese } \\
\text { estimate for the } \\
\text { the GSTP1 par } \\
\text { male subjects } \\
\text { expiratory flow }\end{array}$ & $\begin{array}{l}\text { arameter estimat } \\
\text { variable can be } i \\
\text { timate for mean } f \\
\text { least one copy } \\
\text { forced vital capa }\end{array}$ & $\begin{array}{l} \pm \text { SE. Each model } \\
\text { terpreted as the un } \\
\text { ced expiratory flov } \\
\text { the variant allele ( } \\
\text { ity. }{ }^{*}: p<0.05 \text {. }\end{array}$ & $\begin{array}{l}\text { des height (or height }{ }^{2} \text { ) and we } \\
\text { ange in the lung function measu } \\
\text { ween } 25-75 \% \text { of forced vital } \\
\text { 5) compared with those who }\end{array}$ & $\begin{array}{l}\text { ht as determined } p \\
\text { for subjects carryir } \\
\text { acity ( } F E F 25-75 \% \text { ) } \\
\text { homozygous for } t\end{array}$ & $\begin{array}{l}\text { eviously [11] anc } \\
\text { the variant allele } \\
\text { a be interpreted } \\
\text { e wild-type allele }\end{array}$ & $\begin{array}{l}\text { race/ethnicity. The parameter } \\
\text { of the genotype. For example, } \\
\text { s a decrease in } 23 \mathrm{~mL} \cdot \mathrm{s}^{-1} \text { for } \\
\text { le105). FEF75\%: mean forced }\end{array}$ \\
\hline
\end{tabular}

Conversely, the data suggest that this genotype may have a protective effect in females. This sex difference in the effect of the GSTP1 Val105 variant genotype may help explain the finding of greater male sensitivity to $\mathrm{O}_{3}$-induced lung function changes, which was previously reported by the current authors [11]. Although the possible mechanism for such sex-specific modification can only be speculated upon, GSTP1 is known to have sex-specific patterns of expression [36, 37].

Previously, the current authors have shown that the deleterious effect of $\mathrm{O}_{3}$ on lung function was dependent on intrinsic airway size (measured by the FEF25-75\%/FVC ratio) [33, 34], with a more deleterious effect of $\mathrm{O}_{3}$ on lung function occurring in subjects with smaller airway size [11]. In the present study, in a model that includes antioxidant enzyme genotypes as well as the $\mathrm{FEF} 25-75 \% / \mathrm{FVC}$ ratio, the results show that the deleterious effect of $\mathrm{O}_{3}$ on lung function remains dependent on airway size.

GILLILAND et al. [27] have studied a large group of subjects from the CHS in Southern California and found that non-Hispanic white children with GSTM1 null genotype had a lower rate of

TABLE 4 Genotype and ozone exposure model of lung function (adjusted for airway size and race/ethnicity)

Parameter estimates

\begin{tabular}{|c|c|c|c|c|c|}
\hline \multicolumn{3}{|c|}{ Males } & \multicolumn{3}{|c|}{ Females } \\
\hline GSTP1 Val105 & GSTM1-null & $\begin{array}{c}\text { GSTM1-null/NQO1 } \\
\text { Pro187 }\end{array}$ & GSTP1 Val105 & GSTM1-null & $\begin{array}{c}\text { GSTM1-null/NQO1 } \\
\text { Pro187 }\end{array}$ \\
\hline
\end{tabular}

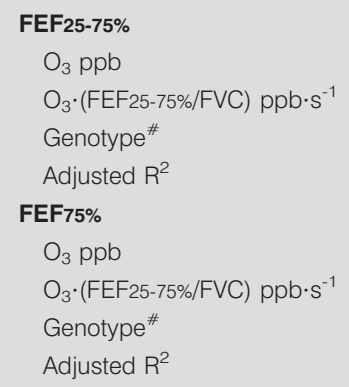

$-0.023 \pm 0.002$
$0.021 \pm 0.002$
$-0.011 \pm 0.024$
0.73
$-0.021 \pm 0.005$
$0.022 \pm 0.003$
$-0.013 \pm 0.043$
0.74
$0.020 \pm 0.001$ $-0.001 \pm 0.023$ 0.73 $-0.020 \pm 0.002$
$0.020 \pm 0.001$
$0.008 \pm 0.022$ 0.73

$-0.018 \pm 0.004$ $0.019 \pm 0.002$ $-0.075 \pm 0.035^{\star}$ 0.69

$\begin{array}{ccc}-0.025 \pm 0.003 & -0.026 \pm 0.003 & -0.024 \pm 0.005 \\ 0.023 \pm 0.002 & 0.024 \pm 0.002 & 0.023 \pm 0.002 \\ 0.005 \pm 0.030 & 0.016 \pm 0.029 & -0.054 \pm 0.041 \\ 0.70 & 0.70 & 0.71\end{array}$

Data are presented are parameter estimate $\pm \mathrm{SE}$. Each model includes height (or height ${ }^{2}$ ), weight and lifetime total exposure to $\mathrm{NO}_{2}$ - and particles with a $50 \%$ cut-off aerodynamic diameter of $10 \mu \mathrm{m}$, as determined previously [11], and race/ethnicity. Only $\mathrm{O}_{3}$-specific and genotype parameter estimates are shown; the full model can be found in the online supplement. FEF25-75\%: mean forced expiratory flow between 25-75\% of FVC; FVC: forced vital capacity; FEF 75\%: mean forced expiratory flow at 75\% of FVC. ${ }^{*}$ : unit of measurement is change in lung function measure for subjects carrying variant allele of each polymorphism. ${ }^{*}: p<0.05 .{ }^{\bullet}: p<0.15$. 
lung function growth. The results from male subjects of the present cohort are consistent with those of the CHS study. However, the analysis presented by the CHS investigators was not stratified by sex. Therefore, the role of sex in modifying the effects of enzyme genotypes on growth of lung function warrants further investigation.

Several studies have suggested an association between $\mathrm{O}_{3}$ induced airway oxidative injury and certain antioxidant enzyme genetic polymorphisms in nonasthmatic subjects, specifically with the GSTM1 null alone and the GSTM1 null/ NQO1 wild-type combination genotypes. In a small field study, BERGAMASCHI et al. [21] showed an association between the $\mathrm{O}_{3}$ level in ambient air and decrements in lung function and changes in plasma CC16 in individuals with the GSTM1 null/NQO1 wild type-combination genotype only. Later, in a controlled exposure study, the same group of investigators showed a differential change in some biomarkers of oxidative stress after $\mathrm{O}_{3}$ exposure between subjects with the GSTM1 null/NQO1 wild-type combination genotype and those with other genotypes [38]. The results of the current authors' chronic exposure study also suggest that females with the combined GSTM1 null/NQO1 wild-type combination genotype have increased susceptibility to $\mathrm{O}_{3}$-related remodelling of the small airways.

The lack of concordant findings with regard to male subjects may be due to multiple differences between the Italian studies $[21,38]$ and the present study. BERGAMASCHI et al. [21] and CORRADI et al. [38] studied the effects of acute $\mathrm{O}_{3}$ exposure while the current authors studied the effect of chronic lifetime exposure. The sample size of the present study is also much larger, potentially allowing sex-specific differences to be uncovered in the gene-environment interaction. In addition, the racial/ethnic composition of the study populations is most likely quite different, since the present population included Asian and Hispanic subjects, who were probably not represented in the Italian studies.

The genetic background of subjects from different selfidentified racial/ethnic groups, which includes their genotypes for other antioxidant enzymes, probably plays an important role in determining their responses to $\mathrm{O}_{3}$ exposure. Population stratification, which can cause spurious associations in candidate gene-association studies, exists when the total population has been formed by admixture of two or more ancestral populations and when admixture proportions vary among individuals. If the risk of the outcome varies with ancestry proportions, then admixture will confound associations of the outcome with genotypes at any locus where allele frequencies vary between ancestral populations. Because genotype frequencies for the three candidate genes varied across racial/ethnic groups (table 2), race/ethnicity was adjusted for in the regression models. However, inclusion of race/ethnicity in the models had little impact on the results (data not shown). Additionally, exclusion of the 16 subjects that did not self-identify as Asian, Caucasian or Hispanic did not significantly change the results of the analyses.

The current authors acknowledge several limitations of the study. First, while larger than many of the other studies that have assessed the effects of the GSTM1 null, GSTM1 null/NQO1 wild-type combination and GSTP1 Val105 genotypes on response to oxidant pollutants, the present study population is too small to definitely assess gene-environment interactions, especially if sex-specific modification is present. Secondly, other genes that were not studied are likely to play a role in determining susceptibility to chronic exposure to $\mathrm{O}_{3}$. Finally, although the current authors attempted to control for population stratification by including self-identified race/ethnicity in regression models, the use of genetic markers might have improved the ability to do so.

In conclusion, it was found that the GSTP1 Val105 variant genotype increases the risk of deleterious effects of chronic exposure to ozone on measures of lung function that reflect small airway remodelling in a group of healthy adolescent males. However, it was also found that this genotype may have a protective effect in their female counterparts. Unlike previous reports from smaller studies of acute exposures, the current authors did not find the GSTM1 null genotype in either sex or the GSTM1 null/NQO1 wild-type combination genotype in males to be associated with decreased lung function due to chronic exposure to ozone. However, it was found that the GSTM1 null/NQO1 wild-type combination genotype increases the risk of ozone-related loss of mean forced expiratory flow between $25-75 \%$ of forced vital capacity in females. The results of the present study suggest that the effects of antioxidant enzyme gene polymorphisms on the risk of decreased lung function related to chronic exposure to ozone may be modified by sex-specific factors.

\section{ACKNOWLEDGEMENTS}

The authors greatly appreciate the expert assistance of $\mathrm{K}$. Beckman (Children's Hospital of Oakland, Oakland, CA, USA) and M. Bastaki (University of California, Berkeley, CA, USA) in the genotyping, the dedication of research assistants L. Carlton, J. Murphy and S. Deamer (all University of California), and the participation of the University of California students who made the study possible.

\section{REFERENCES}

1 Mudway IS, Kelly FJ. Ozone and the lung: a sensitive issue. Mol Aspects Med 2000; 21: 1-48.

2 Gerrity TR, Weaver RA, Berntsen J, House DE, O'Neil JJ. Extrathoracic and intrathoracic removal of $\mathrm{O}_{3}$ in tidalbreathing humans. J Appl Physiol 1988; 65: 393-400.

3 Overton JH, Graham RC, Miller FJ. A model of the regional uptake of gaseous pollutants in the lung. II. The sensitivity of ozone uptake in laboratory animal lungs to anatomical and ventilatory parameters. Toxicol Appl Pharmacol 1987; 88: 418-432.

4 Pryor WA. How far does ozone penetrate into the pulmonary air/tissue boundary before it reacts? Free Radic Biol Med 1992; 12: 83-88.

5 Pryor WA, Squadrito GL, Friedman M. A new mechanism for the toxicity of ozone. Toxicol Lett 1995; 82-83: 287-293.

6 Pryor WA, Squadrito GL, Friedman M. The cascade mechanism to explain ozone toxicity: the role of lipid ozonation products. Free Radic Biol Med 1995; 19: 935-941.

7 Aris RM, Christian D, Hearne PQ, Kerr K, Finkbeiner WE, Balmes JR. Ozone-induced airway inflammation in human 
subjects as determined by airway lavage and biopsy. Am Rev Respir Dis 1993; 148: 1363-1372.

8 Christian DL, Chen LL, Scannell CH, Ferrando RE, Welch BS, Balmes JR. Ozone-induced inflammation is attenuated with multiday exposure. Am J Respir Crit Care Med 1998; 158: 532-537.

9 Arjomandi M, Witten A, Abbritti E, et al. Repeated exposure to ozone increases alveolar macrophage recruitment into asthmatic airways. Am J Respir Crit Care Med 2005; 172: 427-432.

10 Künzli N, Lurmann F, Segal M, Ngo L, Balmes J, Tager IB. Association between lifetime ambient ozone exposure and pulmonary function in college freshmen - results of a pilot study. Environ Res 1997; 72: 8-23.

11 Tager IB, Balmes J, Lurmann F, Ngo L, Alcorn S, Künzli N. Chronic exposure to ambient ozone and lung function in young adults. Epidemiology 2005; 16: 751-759.

12 Koren HS, Devlin RB, Graham DE, et al. Ozone-induced inflammation in the lower airways of human subjects. Am Rev Respir Dis 1989; 139: 407-415.

13 Halliwell B. Antioxidant defence mechanisms: from the beginning to the end (of the beginning). Free Radic Res 1999; 31: 261-272.

14 MacNee W. Pulmonary and systemic oxidant/antioxidant imbalance in chronic obstructive pulmonary disease. Proc Am Thorac Soc 2005; 2: 50-60.

15 Kelly FJ. Vitamins and respiratory disease: antioxidant micronutrients in pulmonary health and disease. Proc Nutr Soc 2005; 64: 510-526.

16 Kleeberger SR. Genetic susceptibility to ozone exposure. Toxicol Lett 1995; 82-83: 295-300.

17 McDonnell WF. Intersubject variability in human acute ozone responsiveness. Pharmacogenetics 1991; 1: 110-113.

18 Balmes JR, Chen LL, Scannell C, et al. Ozone-induced decrements in FEV1 and FVC do not correlate with measures of inflammation. Am J Respir Crit Care Med 1996; 153: 904-909.

19 Strange RC, Spiteri MA, Ramachandran S, Fryer AA. Glutathione-S-transferase family of enzymes. Mutat Res 2001; 482: 21-26.

20 Gilliland FD, Li YF, Dubeau L, et al. Effects of glutathione $S$-transferase M1, maternal smoking during pregnancy, and environmental tobacco smoke on asthma and wheezing in children. Am J Respir Crit Care Med 2002; 166: 457-463.

21 Bergamaschi E, De Palma G, Mozzoni P, et al. Polymorphism of quinone-metabolizing enzymes and susceptibility to ozone-induced acute effects. Am J Respir Crit Care Med 2001; 163: 1426-1431.

22 Romieu I, Sienra-Monge JJ, Ramírez-Aguilar M, et al. Genetic polymorphism of GSTM1 and antioxidant supplementation influence lung function in relation to ozone exposure in asthmatic children in Mexico City. Thorax 2004; 59: 8-10.

23 Romieu I, Ramirez-Aguilar M, Sienra-Monge JJ, et al. GSTM1 and GSTP1 and respiratory health in asthmatic children exposed to ozone. Eur Respir J 2006; 28: 953-959.
24 Piirila P, Wikman $\mathrm{H}$, Luukkonen $\mathrm{R}$, et al. Glutathione $S$ transferase genotypes and allergic responses to diisocyanate exposure. Pharmacogenetics 2001; 11: 437-445.

25 David GL, Romieu I, Sienra-Monge JJ, et al. Nicotinamide adenine dinucleotide (phosphate) reduced:quinone oxidoreductase and glutathione $S$-transferase M1 polymorphisms and childhood asthma. Am J Respir Crit Care Med 2003; 168: 1199-1204.

26 Gilliland FD, Rappaport EB, Berhane K, et al. Effects of glutathione S-transferase P1, M1, and T1 on acute respiratory illness in school children. Am J Respir Crit Care Med 2002; 166: 346-351.

27 Gilliland FD, Gauderman WJ, Vora H, Rappaport E, Dubeau L. Effects of glutathione-S-transferase M1, T1, and P1 on childhood lung function growth. Am J Respir Crit Care Med 2002; 166: 710-716.

28 Gilliland FD, Li YF, Saxon A, Diaz-Sanchez D. Effect of glutathione-S-transferase M1 and P1 genotypes on xenobiotic enhancement of allergic responses: randomised, placebocontrolled crossover study. Lancet 2004; 363: 119-125.

29 Künzli N, Lurman F, Segal M, Ngo L, Balmes J, Tager IB. Reliability of lifetime residential history and activity measures as elements of cumulative ambient ozone exposure assessment. J Expo Anal Environ Epidemiol 1996; 6: 289-310.

30 Tager IB Künzli N, Lurmann F, Ngo L, Segal M, Balmes J. Methods development for epidemiologic investigations of the health effects of prolonged ozone exposure. Part II. An approach to retrospective estimation of lifetime ozone exposure using a questionnaire and ambient monitoring data (California sites). Res Rep Health Eff Inst 1998; 81: 27-78.

31 Tujague J, Bastaki M, Holland N, Balmes JR, Tager IB. Antioxidant intake, GSTM1 polymorphism and pulmonary function in healthy young adults. Eur Respir J 2006; 27: 282-288.

32 Standardization of Spirometry, 1994 Update. American Thoracic Society. Am J Respir Crit Care Med 1995; 152: 1107-1136.

33 Tager IB, Weiss ST, Munoz A, Welty C, Speizer FE. Determinants of response to eucapneic hyperventilation with cold air in a population-based study. Am Rev Respir Dis 1986; 134: 502-508.

34 Mead J. Dysanapsis in normal lungs assessed by the relationship between maximal flow, static recoil, and vital capacity. Am Rev Respir Dis 1980; 121: 339-342.

35 Pellegrino R, Viegi G, Brusasco et al, Interpretative strategies for lung function tests. Eur Respir J 2005; 26: 948-968.

36 Hoensch H, Peters WH, Roelofs HM, Kirch W. Expression of the glutathione enzyme system of human colon mucosa by localisation, gender and age. Curr Med Res Opin 2006; 22: 1075-1083.

37 Hayes JD, Pulford DJ. The glutathione S-transferase supergene family: regulation of GST and the contribution of the isoenzymes to cancer chemoprotection and drug resistance. Crit Rev Biochem Mol Biol 1995; 30: 445-600.

38 Corradi M, Alinovi R, Goldoni M, et al. Biomarkers of oxidative stress after controlled human exposure to ozone. Toxicol Lett 2002; 134: 219-225. 